for transfusion in our clinical setting. ${ }^{3}$ The benefit of using the lactate level and $\mathrm{ScvO}_{2}$ to initiate and guide early resuscitation, including transfusion, in patients with septic shock may be questioned after the results of recent randomized trials. ${ }^{4,5}$ As compared with the high-quality data from these trials, the results of any post hoc subgroup analyses that we may do are less valid.

Gordillo-Escobar et al. speculate that the age of blood and storage lesion could bias the results of our trial. Transfusion practice in patients with septic shock was not based on the age of blood at the TRISS trial sites. These factors may be important, and data from ongoing randomized trials will help us to understand whether the age of blood affects the outcome of critically ill patients (Standard Issue Transfusion versus Fresher Red Blood Cell Use in Intensive Care [TRANSFUSE] trial [ClinicalTrials.gov number, NCT01638416] and the Age of Blood Evaluation [ABLE] trial [Current Controlled Trials number, ISRCTN44878718]).

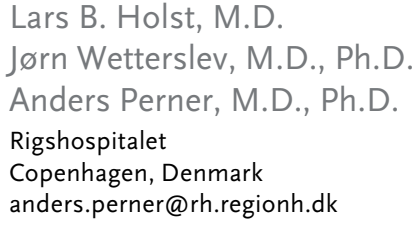

Lars B. Holst, M.D

Jørn Wetterslev, M.D., Ph.D.

Anders Perner, M.D., Ph.D.

Rigshospitalet

Copenhagen, Denmark

anders.perner@rh.regionh.dk

Since publication of their article, the authors report no further potential conflict of interest.

1. DeBaun MR, Gordon M, McKinstry RC, et al. Controlled trial of transfusions for silent cerebral infarcts in sickle cell anemia. N Engl J Med 2014;371:699-710.

2. Holst LB, Haase N, Wetterslev J, et al. Transfusion Requirements in Septic Shock (TRISS) trial - comparing the effects and safety of liberal versus restrictive red blood cell transfusion in patients with septic shock in the ICU: protocol for a randomised controlled trial. Trials 2013;14:150.

3. Rosland RG, Hagen MU, Haase N, et al. Red blood cell transfusion in septic shock - clinical characteristics and outcome of unselected patients in a prospective, multicentre cohort. Scand J Trauma Resusc Emerg Med 2014;22:14.

4. The ProCESS Investigators. A randomized trial of protocolbased care for early septic shock. N Engl J Med 2014;370:1683-93. 5. ARISE Investigators, ANZICS Clinical Trials Group. Goaldirected resuscitation for patients with early septic shock. $\mathrm{N}$ Engl J Med 2014;371:1496-506.

DOI: 10.1056/NEJMc1413474

\title{
Inhaled Glucocorticoids and COPD Exacerbations
}

TO THE EDITOR: In the Withdrawal of Inhaled Steroids during Optimized Bronchodilator Management (WISDOM) study, Magnussen et al. (Oct. 2 issue $)^{1}$ report that the withdrawal of inhaled glucocorticoids had no significant effect on exacerbations in patients with severe chronic obstructive pulmonary disease (COPD), a finding that prompted them to cast doubts about the use of these drugs in such patients. We are concerned about this conclusion because the follow-up of less than 1 year was probably not long enough to assess exacerbations, given that such events occur with an average frequency of 1.3 to 2 per year. In addition, there was a definite trend toward an increase in severe exacerbations after glucocorticoid withdrawal $(\mathrm{P}=0.08)$, which we think conveys an important warning. Perhaps, patients with stage 3 disease (according to the Global Initiative for Chronic Obstructive Lung Disease [GOLD] criteria) should be analyzed separately from those with stage 4 disease to see whether they have different responses. ${ }^{2,3}$ The most worrisome findings were the significant dose- and time-dependent loss of forced expiratory volume in 1 second $\left(\mathrm{FEV}_{1}\right)$ and deterioration in quality of life after the withdrawal of inhaled corticosteroids.

\author{
Manuel Cosio, M.D. \\ McGill University \\ Montreal, QC, Canada \\ manuel.cosio@mcgill.ca \\ Simonetta Baraldo, Ph.D. \\ Marina Saetta, M.D. \\ University of Padua \\ Padua, Italy \\ No potential conflict of interest relevant to this letter was re- \\ ported.
}

1. Magnussen H, Disse B, Rodriguez-Roisin R, et al. Withdrawal of inhaled glucocorticoids and exacerbations of COPD. N Engl J Med 2014;371:1285-94.

2. Jenkins CR, Jones PW, Calverley PM, et al. Efficacy of salmeterol/fluticasone propionate by GOLD stage of chronic obstructive pulmonary disease: analysis from the randomised, placebocontrolled TORCH study. Respir Res 2009;10:59.

3. Decramer M, Celli B, Kesten S, Lystig T, Mehra S, Tashkin DP. Effect of tiotropium on outcomes in patients with moderate chronic obstructive pulmonary disease (UPLIFT): a prespecified subgroup analysis of a randomised controlled trial. Lancet 2009; 374:1171-8.

DOI: 10.1056/NEJMc1413308

TO THE EDITOR: Magnussen and colleagues report that stepwise withdrawal of inhaled glucocorticoids had no adverse effect on exacerbation frequency in patients with severe COPD. The decision to exclude from this study patients with no 
previous exacerbations may have led to removal of the most important subgroup to evaluate. In such patients, inhaled glucocorticoids may have successfully prevented exacerbations, so the withdrawal of therapy, even in a stepwise manner, could have led to increased exacerbations. The inclusion of these patients could have altered the noninferiority finding reported in this trial. The fact that inhaled glucocorticoids are widely prescribed in clinical practice suggests that physicians may see value in their use. ${ }^{1,2}$

Aran Singanayagam, M.B., Ch.B.

Sebastian L. Johnston, Ph.D.

Patrick Mallia, Ph.D.

Imperial College London

London, United Kingdom

aransinga@gmail.com

Dr. Singanayagam reports receiving travel grants and lecture fees from GlaxoSmithKline; Dr. Johnston, receiving grants and personal fees from Centocor, Sanofi Pasteur, GlaxoSmithKline, Chiesi, Boehringer Ingelheim, Novartis, Grunenthal, and Synairgen; and Dr. Mallia, receiving travel grants and lecture fees from GlaxoSmithKline and Novartis. No other potential conflict of interest relevant to this letter was reported.

1. Bourbeau J, Sebaldt RJ, Day A, et al. Practice patterns in the management of chronic obstructive pulmonary disease in primary practice: the CAGE study. Can Respir J 2008;15:13-9.

2. Lucas AE, Smeenk FW, Smeele IJ, van Schayck CP. Overtreatment with inhaled corticosteroids and diagnostic problems in primary care patients, an exploratory study. Fam Pract 2008;25: 86-91.

DOI: $10.1056 /$ NEJMc1413308

TO THE EDITOR: We are concerned that a readily identifiable subgroup of patients with COPD who participated in the WISDOM study were put at risk when their inhaled glucocorticoid was withdrawn. Sputum evidence of eosinophilic airway inflammation is present in 20 to $30 \%$ of patients with COPD during stable periods and acute exacerbations. ${ }^{1}$ These patients have a good shortterm and long-term response to glucocorticoids, and a raised blood eosinophil count has been shown to be a good biomarker of this pattern of airway inflammation. ${ }^{1}$ An increased peripheralblood eosinophil count is associated with an increased risk of death from $\mathrm{COPD}^{2}$ and with a better response to oral prednisolone in patients with a moderate ${ }^{3}$ or severe ${ }^{4}$ exacerbation. Patients with a raised blood or sputum eosinophil count may therefore have a poor response to the withdrawal of inhaled glucocorticoids. The authors measured full blood counts and sputum inflammatory-cell counts in a subgroup of patients. We suggest that assessing the outcome of inhaled glucocorticoid withdrawal in patients who are stratified according to the baseline blood or sputum eosinophil count is an important priority.

\section{Christopher E. Brightling, Ph.D.}

University of Leicester

Leicester, United Kingdom

ceb17@le.ac.uk

Ian D. Pavord, D.M.

Mona Bafadhel, Ph.D.

University of Oxford

Oxford, United Kingdom

Dr. Brightling reports receiving grants from Novartis, Roche, GlaxoSmithKline, MedImmune, AstraZeneca, and Chiesi and through his institution receiving consulting fees from Novartis, Roche, GlaxoSmithKline, MedImmune, AstraZeneca, Almirall, Boehringer Ingelheim, and Chiesi; Dr. Pavord, receiving personal fees from GlaxoSmithKline, AstraZeneca, Novartis, Boehringer Ingelheim, and Aerocrine; and Dr. Bafadhel, receiving travel fees from Almirall, Boehringer Ingelheim, and GlaxoSmithKline. No other potential conflict of interest relevant to this letter was reported.

1. Bafadhel M, McKenna S, Terry S, et al. Acute exacerbations of chronic obstructive pulmonary disease: identification of biologic clusters and their biomarkers. Am J Respir Crit Care Med 2011;184:662-71.

2. Hospers JJ, Schouten JP, Weiss ST, Rijcken B, Postma DS. Asthma attacks with eosinophilia predict mortality from chronic obstructive pulmonary disease in a general population sample. Am J Respir Crit Care Med 1999;160:1869-74.

3. Bafadhel M, McKenna S, Terry S, et al. Blood eosinophils to direct corticosteroid treatment of exacerbations of chronic obstructive pulmonary disease: a randomized placebo-controlled trial. Am J Respir Crit Care Med 2012;186:48-55.

4. Bafadhel M, Davies L, Calverley PM, Aaron SD, Brightling $\mathrm{CE}$, Pavord ID. Blood eosinophil guided prednisolone therapy for exacerbations of COPD: a further analysis. Eur Respir J 2014;44:789-91.

DOI: 10.1056/NEJMc1413308

THE AUTHORS REPLY: Cosio et al. are concerned that our study follow-up may not have been long enough to assess an increased risk of exacerbations because of a low annual frequency of such events. Our study was powered to show noninferiority with regard to moderate or severe exacerbations on the basis of an estimated number of events to be observed, and there was no timedependent increase in these events (as shown in Fig. 2A of our article). As for the observed numerical increase in severe exacerbations, this was a transient increase after inhaled glucocorticoids were completely stopped. However, as shown in Figure $2 \mathrm{C}$ of our article, this difference was not maintained, and the overall event rate was similar in the two groups. We present the analysis according to GOLD stage in Figure 3 of our article, and there was no significant between-group 
difference. The observed loss of $\mathrm{FEV}_{1}$ was neither a time-dependent nor a dose-dependent effect in the withdrawal group, as compared with the maintenance group. A difference of $38 \mathrm{ml}$ between groups became apparent only after the final step of inhaled glucocorticoid withdrawal and did not change to a meaningful extent thereafter.

Singanayagam et al. point out that we included only patients receiving maintenance therapy with inhaled glucocorticoids who had a history of exacerbation in the previous year. This reflects current treatment recommendations. In the recent Indacaterol: Switching Nonexacerbating Patients with Moderate COPD from Salmeterol/ Fluticasone to Indacaterol (INSTEAD) trial involving patients with moderate COPD who had no exacerbations during the previous year, switching patients from a combination of a long-acting $\beta$-agonist (LABA) and an inhaled glucocorticoid to an ultra-long-acting LABA did not increase the exacerbation rate during 26 weeks of treatment. ${ }^{1}$ We agree that clinicians prescribe inhaled glucocorticoids because they see value in their use, but there may be reasons other than the prevention of exacerbations for this practice, such as the convenience of combination inhalers. ${ }^{2}$

Brightling et al. suggest that we stratify our results according to the baseline blood eosinophil count. A major objective of the WISDOM trial was to identify a subgroup of patients who have a response to inhaled glucocorticoids, ${ }^{3}$ but so far we have not been able to identify a responsive phenotype on the basis of data from our prespecified subgroups.

\section{Helgo Magnussen, M.D. \\ Pulmonary Research Institute Grosshansdorf, Germany magnussen@pulmoresearch.de \\ Kay Tetzlaff, M.D. \\ Boehringer Ingelheim Pharma Ingelheim, Germany \\ Peter M.A. Calverley, M.D. \\ University of Liverpool \\ Liverpool, United Kingdom}

Since publication of their article, the authors report no further potential conflict of interest.

1. Rossi A, van der Molen T, Olmo RD, et al. INSTEAD: a randomised switch trial of indacaterol versus salmeterol/fluticasone in moderate COPD. Eur Respir J 2014;44:1548-56.

2. Vogelmeier CF, Bateman ED, Pallante J, et al. Efficacy and safety of once-daily QVA149 compared with twice-daily salmeterol-fluticasone in patients with chronic obstructive pulmonary disease (ILLUMINATE): a randomised, double-blind, parallel group study. Lancet Respir Med 2013;1:51-60. [Erratum, Lancet Respir Med 2013;1:101.]

3. Magnussen $\mathrm{H}$, Watz H, Kirsten A, et al. Stepwise withdrawal of inhaled corticosteroids in COPD patients receiving dual bronchodilation: WISDOM study design and rationale. Respir Med 2014;108:593-9.

DOI: 10.1056/NEJMc1413308

\section{Fractional Flow Reserve-Guided PCI}

TO THE EDITOR: De Bruyne et al. (Sept. 25 issue) ${ }^{1}$ conclude that the high rate of death within 7 days after randomization in the percutaneous coronary intervention (PCI) group in their study was due to benign periprocedural infarctions, but there were more myocardial infarctions in the medicaltherapy group after the initial 7 days following randomization. However, after 7 days, there were more revascularizations in the medical-therapy group; this suggests that there were more periprocedural infarctions. ${ }^{2}$ Thus, the high rate of myocardial infarctions after the initial 7 days following randomization in the medical-therapy group could also be caused by the same benign periprocedural infarctions, since there was no difference in overall mortality. ${ }^{2}$ Unfortunately, the percentage of late myocardial infarctions caused by periprocedural infarctions was not reported.
Furthermore, the primary outcome in this study was driven mainly by urgent revascularization, which could have been confounded by the open-label nature of the study. Since patients in the medical-therapy group knew that they had untreated stenosis, they were more likely to report symptoms. ${ }^{3}$ Coupled with bias from treating physicians, this would lead to a higher incidence of hospitalization, cardiac catheterization, and ultimately revascularization. ${ }^{4}$ Therefore, a double-blind, controlled trial is required to determine the true effect of fractional flow reserve-guided PCI on urgent revascularization. ${ }^{5}$

Rahman Shah, M.D.

University of Tennessee

Memphis, TN

No potential conflict of interest relevant to this letter was reported. 